\title{
Chronic Respiratory Allergy Caused by Lophomonas blattarum: A Case Report
}

Oghlniaz Jorjani (PhD)

Laboratory Sciences Research Center, Faculty of Paramedicine, Golestan University of Medical Sciences,

Gorgan, Iran

Abdolrahman Bahlkeh (MSc)

Central Laboratory, Azadshahr Health Center, Golestan University of Medical Sciences, Gorgan, Iran

Faramarze Koohsar $(\mathbf{P h D})$

Laboratory Sciences Research Center, Faculty of Paramedicine, Golestan University of Medical Sciences,

Gorgan, Iran

Beniamin Talebi (DVM)

Private veterinary physician, Gorgan, Iran

Ali Bagheri (MD)

Communicable Disease Control of

Health Center, Golestan University of

Medical Sciences, Gorgan, Iran

Corresponding author: Oghlniaz

Jorjani

Email: niaz_jorjani@yahoo.com

Address: Laboratory Sciences

Research Center, Faculty of

Paramedicine, Golestan University of

Medical Sciences, Gorgan, Iran

Received : 21 Oct 2017

Revised: 05 Dec 2017

Accepted: 26 Dec 2017

Oghlniaz Jorjani http://orcid.org/0000-0003-2426-

2956

\section{ABSTRACT}

Background and 0bjective: Lophomonas blattarum is a multi-flagellate protozoan that is commensal in hindgut of cockroaches and other insects. The protozoan can cause respiratory infection in humans. Most cases of the infections with this protozoan have been reported in China. Here, we present a case with chronic respiratory allergy caused by $L$. blattarum in Golestan province, Iran.

Case Description: The case was a 37-year-old male with history of respiratory conditions and he was immunocompetent. An athlete. L. blattarum was detected in direct smear examination of sputum,

Conclusion: Since we found respiratory infection in an immunocompetent individual who was also an athlete, it is necessary to study this parasite and its life cycle and transmission methods. It is also suggested to consider L. blattarum infection and treatment with metronidazole in cases of chronic allergies, especially those that do not respond to treatment.

Keywords: Lophomonas blattarum, Respiratory Allergies, Iran.

This paper should be cited as Jorjani O, Bahlkeh A, Koohsar F, Talebi B, Bagheri A[Chronic Respiratory Allergy Caused by Lophomonas blattarum: A Case Report ]. mljgoums. 2018; 12(2):44-46 


\section{INTRODUCTION}

Lophomonas blattarum is a multiflagellate, round to oval shape protozoan with diameter of 20-60 $\mu \mathrm{m}$. At one pole, the protozoon has a tuft of numerous flagella. This anaerobic protozoan from phylum Parabasalia, order hypermastigida and suborder Lophomonadidae is a commensal of hindgut of cockroaches, termites and omnivorous roaches, and probably involved in facilitation of digestion (1). Respiratory symptoms and lung infection by L. blattarum is rare in humans. Several cases have been reported in China and a few cases have been found in Spain, Peru and Turkey (2-5). In Iran, the first case of respiratory infection caused by L. blattarum was reported in 2014. The case was a young female who was admitted to the hospital because of sinusitis and respiratory symptoms (6). Here, we report a case of chronic respiratory allergies caused by $L$. blattarum in Iran.

\section{CASE DESCRIPTION}

A 37-year-old male with history of respiratory conditions including asthma, cough and wheezing, shortness of breath and sputum after exercise, especially in the cold season was referred to the Diagnostic Laboratory of Tuberculosis in east of Golestan province, Iran. Moving flagellated protozoa were observed in direct smear sputum examination. The case was referred to the Department of Medical Laboratory Science at Golestan University of Medical Sciences on August 26, 2016. Further evaluations were made in the parasitology laboratory, and a number of $L$. blattarum was detected in the direct smear sputum examination by light microscopy (Figure1). The protozoon has an irregular orientation and loses the power of movement after 15-20 minutes. The patient reported that he had seen cockroaches in his home. The case was immunocompetent and played football regularly. White blood cell count was $6.4 \times 10^{3}$ cells/L with $2 \%$ eosinophils. Erythrocyte sedimentation rate was 8 and C-reactive protein was negative. Culture of sputum for diagnosis of Mycobacterium tuberculosis was negative. Moreover, sample culture in sabouraud dextrose agar for detection of fungi was negative. Chest X-ray was normal. Direct sputum smear examination for diagnosis of tuberculosis was negative. The patient was treated with metronidazole $750 \mathrm{mg}$ t.i.d for 15 days.

\section{DISCUSSION}

Bronchopulmonary L. blattarum infection has been reported in some countries, especially China. Most cases have been observed in immunosuppressed individuals (7).

However, infection with this protozoan has been recently observed in immunocompetent young adults (8). Since we found respiratory infection in an immunocompetent individual who was also an athlete, it is necessary to study this parasite and its life cycle and transmission methods (1, 5). In addition, physicians are advised to consider infection with this parasite, especially in allergic respiratory disorders. Chronic respiratory allergies caused by the parasite can be treated with metronidazole.

Figure1 -Presence of $L$. blattarum in direct sputum smear examination by light microscopy (at 40X magnification)
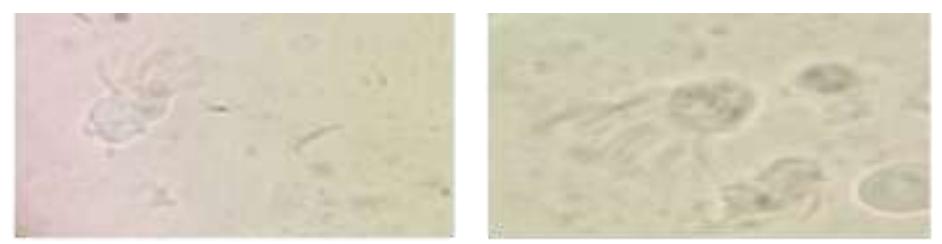

\section{CONCLUSION}

It is suggested that L. blattarum infection be treated with metronidazole in cases of chronic allergies, especially those that do not respond to treatment.

\section{CONFLICT OF INTEREST}

The authors declare no conflict of interest. 


\section{REFERENCES}

1. Martinez-Girón R, van Woerden HC. Lophomonas blattarum and bronchopulmonary disease.

J Med Microbiol. 2013; 62(Pt 11): 1641-8. doi: 10.1099/jmm.0.059311-0.

2. He Q, Chen X, Lin B, Qu L, Wu J, Chen J. Late onset pulmonary Lophomonas blattarum infection in renal transplantation: a report of two cases. Intern Med. 2011; 50(9): 1039-43.

3. Nie XM, Yao XP, Huang Y, Zhou DY, Chang ZS, Li Q. Amiodarone pneumonitis with Hypermastigote lung infection: a case report and review of the literatures. Zhonghua Jie He He Hu Xi Za Zhi. 2006; 29(5): 310-2.

4. Zhou YP, Zhu XJ, Li M, Liu H, Chen YS. Clinical analysis of bronchopulmonary infection with hypermastigotes: a report of two cases and review of the Chinese literature. Zhonghua Jie $\mathrm{He} \mathrm{He} \mathrm{Hu} \mathrm{Xi} Z \mathrm{Za} Z$ Zhi. 2006; 29(1): 23-5.
5. Martínez-Girón R, Esteban JG, Ribas A, Doganci L. Protozoa in respiratory pathology: a review. Eur Respir J. 2008; 32(5): 1354-70. doi: 10.1183/09031936.00022008

6. Berenji F, Parian M, Fata A, Bakhshaee M, Fattahi F. First Case Report of Sinusitis with Lophomonas blattarum from Iran. Case Rep Infect Dis. 2016:2614187. doi: 10.1155/2016/2614187.

7. Kilimcioglu AA, Havlucu Y, Girginkardesler N, Celik $\mathrm{P}$, Yereli K, Özbilgin A. Putative bronchopulmonary flagellated protozoa in immunosuppressed patients. Biomed Res Int. 2014; 2014: 912346. doi: $10.1155 / 2014 / 912346$

8. Yao G, Zhou B, Zeng L. Imaging characteristics of bronchopul-monary Lophomonas blattarum infection: case report and litera- ture review. J Thorac Imaging. 2009; 24(1): 49-51. doi: 10.1097/RTI.0b013e31818c6b72. 